\title{
The Relevance of Networking Strategy in Agribusiness: An Italian Empirical Case Study
}

\author{
Marcello Sansone ${ }^{1}$ \\ ${ }^{1}$ University of Cassino and Southern Lazio, Italy \\ Correspondence: Marcello Sansone, Associate Professor in Marketing, University of Cassino and Southern Lazio, \\ 03043 Cassino - Via Sant’Angelo, loc. Folcara 0776-2994793, Italy. E-mail: m.sansone@unicas.it
}

Received: January 9, 2015 Accepted: March 7, 2015 Online Published: March 28, 2015

doi:10.5539/ijms.v7n2p1 URL: http://dx.doi.org/10.5539/ijms.v7n2p1

\begin{abstract}
This work aims to analyze the role of network business and agglomeration economies in the agribusiness, emphasizing how an integrated marketing strategy generates benefits to entrepreneurs, to the supply chain, to the internal and external stakeholders, increasing the bargaining power of businesses and improving their competitiveness.

The analysis focuses on the agri-food businesses in the Plain of Fucino- an agricultural area in Southern Italy, proceeding with Swot Analysis, and measuring the most significant limitations-in terms of corporate culture, size of company, logistics and distribution capabilities, market dimension, seasonal nature of the work.
\end{abstract}

Finally, in the managerial implications, the Author highlights the strategies through which agribusinesses may exceed the limits identified.

Keywords: network economies, agribusiness, brand strategy, supply chain, place marketing

\section{Introduction and Objectives}

The increasing importance of network economies leads the Author to identify the reasons why some agri-food businesses create an integrated system capable of communicating a unique brand that is nationwide and worldwide successful. This success is based on a shared strategy among the different enterprises, which aims to promote and sell the products of a specific place as a result of a single system. On the other hand it is considered significant focus on major limitations that prevent companies from creating a local network to achieve significant competitive advantages, although tangible and intangible resources can yield excellent products.

The strategic relevance of these topics is highlighted by EU, which has acted in order to promote the integration between businesses, and between them and their understandings, placing these issues at the center of CAP 2014-2020, in which the EU has indicated that it will be difficult to resolve the current situation and the crisis of sales by individual companies.

So in the first part of the paper, the Author describes the conceptual framework on the issue of agglomeration economies and he explains a brief review of the literature. Later, he will proceed to the analysis of an empirical case that has interesting tangible resources and many agri-food businesses, but nonetheless it fails to create an efficient network of businesses and a competitive brand: the plain of Fucino.

The research comes to identify the main limitations to the launch of a branding strategy, through the SWOT analysis method, and to formulate a development strategy immediately applicable to the analyzed place.

\section{Research Question}

This research aims to identify what might be the main reasons why some areas and some networks of agribusinesses fail to plan a comprehensive and integrated brand strategy, which makes recognizable and unique products that by their nature are generally undifferentiated - especially fresh food. The objective is to define the limits for which some enterprises fail to achieve significant competitive advantages while having available discrete areas of production, spatial proximity and natural resources, such as to be potentially excellent food producers.

In particular, the work focuses on the single case of plain of Fucino: after an analysis of secondary data, the Author proceeds with a SWOT analysis in order to highlight the limits to the development of the territory and, in 
a second phase of the research, to prepare a questionnaire to be submitted to agribusiness, in order to plan a development strategy.

\section{Literature Review}

Many studies about network business and agglomeration economies have shown that the cooperation between small and medium-sized enterprises may represent a fundamental choice for their development and their growth; starting from 1972, with the contribution of Pfeffer, many researches demonstrated the importance of inter-organizational relationships such as strategic resource to competitive strengthen of companies.

The term network implies a plurality of relationships formed between different companies that identify them as a means to achieve collective and shared interests (Marchini, 2005).

In the national and international literature the topic of enterprise networks is addressed in an interdisciplinary viewpoint; indeed several lines of research focus on different perspectives from which the phenomenon of relations between businesses - sociological, economic, legal — can be analyzed. The network concept is based on several elements: the boundaries of the system, the individual units, the relational content, the shape of network systems (Rullani, 2008). It is thus possible to distinguish two main types of networks: interpersonal and organizational, in the interpersonal network the most important elements are the individuals who work in the system; in organizational networks companies represent the reference unit. Therefore the set of socio-economic ties that characterize the local business networks originates from the combination of these two types of networks (Granovetter, 1973).

Many authors argue that for successful businesses networking is fundamental understanding of the reasons and how the networks evolve and change over time (Nohria, 1992), in fact-in studies about organization of enterprises - some authors analyzed the evolutionary process of the networks (Gulati \& Gargiulo, 1999; Soda, Usai, \& Zaher, 2004; Yin, Wu, \& Tsai, 2012) and some of the factors that play a significant role in the development of network (Das \& Teng, 2002; Sakakibara, 1997).

The implementation of cooperation through business networks has been considered as an alternative to internal growth that enables small businesses to survive and cope with dynamic and hypercompetitive environments. (Hansenn-Bauer \& Snow, 1996)

The aggregation strategies through the dissemination and the combination of resources and expertise allow to exceed the constraints of the innovative development and production complexity present in some places; some small and medium-size enterprises have managed to stay on the market with competitive products through the adoption of collaborative strategies. The success of these enterprises originates from their market power toward customers; it seems to be attributed to the investments made on the knowledge and the integration of upstream and downstream activities of the supply chain by making use of collaborative processes rather than to efficiency based on production costs (Note 1).

The systemic dimension of the relationship between businesses has been regarded as competitive element in front of the most dynamic markets. According to this debate it is argued that the ability to innovate and compete successfully, especially within industrial districts and local production systems is related not only to the ability of individual firms but rather the network of relations that binds these enterprises in the system (Brusco, 2008).

In Italy, the network concept was born with the phenomenon of industrial district up to evolve into forms of "emerging" network business (Bagnasco \& Rullani, 2008).

The concept of industrial district has been analyzed by some agricultural economists many studies based on the analysis of the issues of the districts originate from the conceptual nature of the agribusinesses linked to the territory and immersed in the local society (Contò \& La Sala, 2011).

Even if the differences between the two contexts of production (industrial and agricultural) are evident in some way-for example, the influence of "land" and "climate" factors on agricultural production and processes, may be irrelevant in the industrial production - it's important to underline two important concepts (Becattini, 1998); first the district is a policy of promoting entrepreneurial skills and production know-how of certain groups of the population, or of local systems. Second, in specific reference to the size of farms, to the dynamics of disintegration or decomposition, to concentration and specialization of production, as well as the strong environmental ties in which the same firms are immersed, it's possible to reflect on the fact that the farms are closer to the industrial district model before the industry, when this one was dominated by large firms.

In fact, like what happened in industry, in agriculture important changes occurred related not only to the role of agriculture in the economic system, but also to the increasing integration with the processing industry; such 
changes are considered as a natural step in the process of development of the sector towards those that can be defined as "local systems of agricultural development", of which the agro-industrial district is a natural subset.

Among the fundamental elements for the recognition of a agro-industrial networks Montresor and Fanfani (1994) emphasize some points essential that involve the presence of typical products, the existence of relationships between agriculture and processing industry, the flexible specialization of production, capacity for innovation and its diffusion, human capital development and the support of local authorities. Also for the identification of districts, specifically for the food industry, location, concentration and specialization indicators have been defined and used (Brasili, Ricci, \& Maccarini, 2001).

Therefore, it is possible to summarize the characteristics of the agricultural and agro-industrial districts in several factors. In the first place the territorial dimension, resulting from the environmental characteristics and the historical and cultural traditions, is connected to a strong territorial connection with regional agricultural enterprises, to the high level of professionalism and specialization of production and finally to the strong complementarity of the supply chain. Also important is the role played by institutions and local authorities, which can act to guarantee and protect the quality of agricultural districts and steer its activities by means of national and regional programming. The existence of a dense network of social relations, economic and institutional reforms, led to the creation of innovation processes that are also peculiar elements of the agro industrial district, along with widespread entrepreneurship and the ability to trigger endogenous development process (Contò \& La Sala, 2011).

In the early stages of formation of a network should be considered the way in which companies respond to exogenous stresses - for example, the uncertainties of the market and endogenous-for example, characteristics and conditions of firms and reasons that drive their development (BarNir \& Smith, 2002; Park, Chen, \& Galagher, 2002).

The specific environmental characteristics of the market — as the complexity of the products and the increasing competitive pressure, the economic trend, the political and social context-have an important impact on the creation of the small businesses' external relations (Street \& Cameron, 2007).

Therefore the complexity of the market favors the inception of interorganisational relationships with the aim to acquire external resources and reduce environmental uncertainty; in particular for small and medium-sized enterprises, external relations are considered to be significant and in some cases also crucial to their survival (BarNir \& Smith, 2002; Bruderl, Preisendorfer, \& Ziegler, 1992). In fact, the small and medium-sized businesses have limited resources and limited market presence and through connections with other businesses they can access the resources they need (Oliver, 1990). These strategic aggregations can be considered a useful mechanism to share and respond to the market competitiveness and sometimes they originate in order to create a block for the defense of competition from other business groups. This happens even when the network is born to prevent potential losses rather than economic benefits (Park \& Zhou, 2005).

Other times they create networks in order to improve the competitive position of their business, to win the strongest competitor and capture opportunities that arise; the network of firms is thus a resource that sometimes goes to compensate the lack of other resources. Entrepreneurs act then proactively and collaboratively in order to generate the development of new businesses; (Park \& Zhou, 2005): there is a link between proactivity of companies and networking among entrepreneurs, proactivity is the entrepreneur's propensity to resort to connections to respond to the external environment and achieve business goals. The most proactive companies are more influenced and induced to networking by the industrial dynamics (Yadong, 2003).

Therefore the inter-relationships enable small and medium companies to implement quality development paths without necessarily growing by expansion (Marchini, 2005). Such relationships shorten development time and allow enterprises to get all the advantages of vertical and horizontal integration and diversification (Anderson et al., 1994); thus collaborative relationships represent a form of strategic development and organizational of businesses (Lorenzoni, 1990; Rullani, 2008).

Other Authors consider network business as a driver of structural and strategic flexibility, as well as radical and innovative learning tool that allows small businesses to weaken the position of competitors, or to strengthen the strategic placement according to those that have offensive or defensive purpose (Harrigan, 1998; Depperu, 1996).

Through the aggregation the companies seek goals that can be defensive, proactive and of strengthening, or a combination of both. However, these goals are connected with the generic strategies-such as diversification 
and competitive strategies - that can come in contact faster and more effectively by the network business. (Anderson et al., 1994).

In conclusion it's possible to summarize the reasons that can encourage companies to create a network: the networks support businesses managing the complexity of the different input sources; they reinforce the opening of markets, provide the infrastructure for the exchange of innovative knowledge flows, provide advantages of scale and specialization and enhance the reputation and visibility. Likewise the development of interorganizational relationships is considered a quick way to capture the benefits of specialization related to specific stages of the value chain and to reduce competition through relationships with competitors; furthermore, the creation of networks is motivated by the desire to spread the cost of innovation and reduce connected risks.

\section{Method}

The work aims to achieve the results earlier described through an analysis of secondary data that stand for the current state of the agro-food system in Abruzzo, in particular in the plain of the Fucino. The goal is to identify the data more representative of the place, in terms of production, distribution and ability to compete in the agri-food businesses. These data serve as a starting point for further analysis of the tangible and intangible factors, both internal and external to the territory, through the well-known and well-established methodology of SWOT analysis. SWOT analysis is not a new idea in the business practice and in place studies, this model originated from the Harvard Business School (Delahaye, 2000), and has dominated strategic plans since the 1950s (Lerner, 1999). SWOT analysis, that is by far the most popular, can serve a dual function: it can be used for both internal and external environment scanning (Kheng-Hor \& Munro-Smith, 1999; Lerner, 1999).

The swot analysis is a transparent planning instrument enables a company or a place to learn about the current situation and reflect on what can be done to improve the current situation (Sorensen, Vidal, \& Engström, 2004); after analyzing the external and internal environments, the firms are able to decide which competitive strategies should be used to achieve its competitive objective. The competitive strategies could be used to "exploit opportunities in the firm's environment with the firm's strength, and neutralizes threats in the firm's environment while avoiding the firm's weaknesses" (Barney, 2007)

The Author believes that detailed and accurate swot analysis should be the starting point for identifying and implementing the most appropriate strategy of agglomeration of the agri-food businesses in the researched area, that is a place that - although many producers of fruit and vegetables and many material resources to be used - fails to create an integrated and efficient system and subsequently an unique brand. So this work will arrive to the identification of a strategy that can exploit the strengths of the plain of Fucino and eliminate or at least minimize weaknesses and external threats.

\section{Secondary Data Analysis: Abruzzo and Plain of Fucino}

The Fucino is a plateau in the Marsica, situated in the Abruzzo region-Province of L'Aquila-once occupied by a large lake now dried up. The Plain of Fucino is located at an altitude of 650 meters in height and is completely enclosed by mountain ridges consist predominantly of meso-cenozoic carbonate rocks and of miocene terrigenous rocks. In the eastern and north-eastern part of the plain (between Celano and Gioia dei Marsi) fluvio-lacustrine terraces of Plio-Quaternary age are also well developed (Note 2).

The Fucino is an endorheic basin; when it was occupied by the lake it was spread over an area of approximately $155 \mathrm{~km}$ (Note 3) with a maximum depth of $18 \mathrm{~m}$; so it was the third lake in Italy, after Lake Garda and Lake Maggiore. The first project to drain the lake to increase the cultivable area in wheat dates back to Julius Caesar; the roman Imperator Claudio executed it by building an emissary to dispose of the waters of the Fucino in the Liri river. In the Middle Ages the Fucino returned to the condition of closed lake with irregular capacity. The draining was begun in 1852 by a French company, was continued by Duke Alessandro Torlonia and completed in 1885, making again cultivable 16,000 hectares of land. Subsequently, the funds were divided and assigned to peasant families (many of them were immigrants) and the large estates passed to the small landowning. The Fucino basin, currently bounded by the towns of Avezzano, Luco dei Marsi, Trasacco, Ortucchio, San Benedetto dei Marsi, Pescina, Cerchio, Aielli, Celano, is today one of the most economically prosperous of the Abruzzo, even with intensive crops of potatoes, cereals, vegetables, sugar beets that have also enabled various processing industries.

Focusing on agri-food businesses in the Abruzzo region, there has been a decline of $13 \%$ from 2000 to 2010 , the year in which registered companies were almost 67,000 with about 454,000 farming hectares and 687,000 hectares of the total area. Contrary to the results of previous census investigations of 1990 and 2000 , the Abruzzo's agricultural area is increased by $5 \%$, with a recovery of 22,000 hectares concentrated almost everyone 
in the province of L'Aquila, in which the UAA (Utilized Agricultural Area by company) average has grown as a result of $60 \%$, from 14.8 hectares in 2000 to 23.7 in 2010. That increase in size is mainly due to the decrease in the number of companies (30\%); also most companies with large enterprise surfaces are conducted mainly by public institutions and predominantly invested in grazing land and uncultivated.

Despite an increase of $21 \%$ of the UAA average, Abruzzo is characterized, more than other regions of the south-central of Italy, by the existing of many micro-firms. The 78\% of farms in Abruzzo has an agricultural area of less than 5 hectares, half of which are located in the province of Chieti. Companies with an agricultural area exceeding 50 hectares account for just $1.5 \%$ of the total, concentrated almost all in the province of L'Aquila. The companies conducted by a single individual (sole proprietorships) account the majority of farm management both nationally $(76 \%)$ and regional $(71 \%)$. In terms of agricultural area significant differences are indicated between the province of L'Aquila and the other three provinces; in fact in L'Aquila Area the $40 \%$ of the UAA is held by companies belonging to public bodies and other legal entities, net of which, the UAA of L'Aquila's companies down to 14.3 hectares.

The labour force employed in the regional agricultural sector is still characterized by the overwhelming predominance of family labour, which covers more than $85 \%$ of agricultural employment. In line with the national average, even in Abruzzo over a third of companies is led by people over sixty (37.2\% for Italy and $38.7 \%$ for Abruzzo).

On average, Abruzzo's companies have realized a standard production equal to 19,500 euro, higher than that of the southern regions but lower than the national average (31,000 euro), according to data from the Census of 2010. The average of Abruzzo is similar to the EU-27 average (23 thousand euro to standard production company).

In terms of economic size Abruzzo's farms are concentrated for more than $85 \%$ below the threshold of 25,000 euro of SP and over 45,000 of these companies (68\%) have an economic size lower than 8000 euro of standard production. At the national level, however, the small and medium-small ones represent respectively $62 \%$ and $19 \%$ of the total of companies classified.

In 2011, according to the annual report of the CRESA (Note 4), it has been a bad year for the general economy of the Abruzzo region, with a GDP decline, albeit slight (-0.2\%), but in contrast to the signs of recovery at the national level $(+0.4 \%)$. The positive indicators were mainly focused on the excellent results of exports, higher than the national average growth rate, on the increase in the number of active enterprises, particularly corporations, and on the positive trend of the labour market, the best the southern regions, but they went down in the agricultural sector. According to the data of Infocamere, Abruzzo farms active in 2011 were 30,500 units; this data show a decrease of $2 \%$ compared to 2010 . The farms represent $23 \%$ of the 133,000 companies registered in the archives of the Chambers of Commerce of Abruzzo.

The composition of the regional agricultural production, compared to the national average data, consists of a prevalence of segment of crops ( $62 \%$ versus 53\% of national incidence, average data from 2009 to 2012), and consequently of a lower incidence of farms animals (14\% versus $33 \%$ nationally). The value of production of field crops (498 million euro) is equal to $65 \%$ of the regional production (in Italy 54\%), while $32 \%$ (342 million euro) is given by the tree crops ( $40 \%$ national incidence), and the remaining 3\% from forage ( 23 million euro). Among the herbaceous crops, horticultural crops (including potatoes) prevail ( $74 \%$ compared to a national average incidence of 50\%) with 368 million euro of value production and grains, with a result in 2012 equal to 106 million euro, that represent $21 \%$ of the value of the annual production of field crops in front of a national incidence of $35 \%$.

Therefore, in addition to wine and oil with various typical products, most economic representative productions, are composed by the vegetables division; in this section the Abruzzo holds more than $26 \%$ of the national production of both carrots salad, all concentrated in Fucino.

In particular, in 2013 only in the Fucino Plain were cultivated 13,548 hectares of agricultural land, of which the largest part (3,812 hectares) is used for the production of potatoes, which correspond to a total of the direct costs equal to 24,880,924 Euro per year. The cultivation of carrots is the most important in terms of produced quantity, with a total production of 1,960 tonnes per year, followed by 1,524 tonnes of potatoes and 1,378 tonnes of corn. In 2012, in Fucino, were registered with the chamber of commerce, 2,167 agriculture businesses, including 1185 farmers and 406 employees registered with INPS (Note 5). In the same year permanent employees amounted to 700 units, compared to 8,500 temporary employees, for a total of 600,000 days of employment and a total agricultural GDP of 450 million euro. In general Confagricoltura L'Aquila estimate total employment in the sector in the only area of the Fucino that equal to 1500 units. 
Compared to the national trend Abruzzo had high growth rates for the export of food products, although in relative terms Abruzzo has a low weight on the Italian commercial agribusiness scale $(1.5 \%$ of exports and $1.1 \%$ of imports). In absolute terms, exports of food products have passed the 370 million euro, $83 \%$ of which are agro-products, and only 54 million euro are agricultural products ( $10 \%$ of Value Added).

Exports are mainly represented by the products of the milling industry and in particular of the pasta industry, followed by the beverage, which in Abruzzo essentially is settled by wine, with a total value of 113 million euro.

\section{Results and Discussion}

Based on the conducted analysis of secondary data and on field surveys, it has come to summarize the main factors endogenous and exogenous of the area in question through a SWOT analysis.

\begin{tabular}{ll}
\hline Strengths & Weaknesses \\
\hline - Presence of significant natural and historical resources; & - Excessive fragmentation of enterprises; \\
- Increase of the utilized agricultural area in the province of & - Lack of organizational forms district; \\
L'Aquila; & - Agribusiness size below the national average; \\
- Share of women in employment higher than in the domestic & - Tiny turnover; \\
agricultural sector; & - Competing use of resources among present activities; \\
- Mortality rate of agribusiness lower than the average of the & - Inadequate infrastructural and logistical equipment; \\
economy; & - High number of business conducted by a single person (71\%); \\
- Fertile Territory; & - Low percentage of diversified companies; \\
- PGI Carrots; & \\
\hline Opportunities & Threats \\
\hline - CAP 2014-2020; & - High competition on national and international markets; \\
- Growth rate of exports above the regional average; & - Agricultural entrepreneurs of Abruzzo with high average age \\
- Growth in the number of young people who are approaching the & (more than a third are over sixtyfive); \\
world of agriculture; & - Significant decline in the number of regional agri-food businesses; \\
- Improvement of production capacities; & - Very low values of exports than the national average; \\
- Presence of some large agro-businesses; & - Lack of tools for planning long-term strategic. \\
\hline
\end{tabular}

Some factors are particularly important in order to understand the limits to growth in the area of Fucino and to formulate hypotheses for the development of this territory: the analyzed data and the surveys conducted show excessive fragmentation of Fucino's agri-food businesses that are numerous, but with lower profits than the national average, of which a high percentage is even lower to 8,000 euro per year.

Furthermore, it is evident the lack of appropriate structures, both times to the increase of production efficiency, both in logistics terms for the distribution and the export of the products. However, the tangible resources and production data suggest that the Fucino area can achieve substantial growth trends, if it implements an integrated and shared development plan. Considering the analysis of conceptual and theoretical framework, and the benefits identified in the literature review, related to network economies in the agri-food businesses, it is believed that the most effective organizational and strategic solution is certainly an organizational model based on a network of agri-food businesses.

Concerning the promoter subject it seems several alternatives: on the one hand the Public institutions-Region, Province, Confagricoltura - could convey and implement such project, on the other hand it shows the presence of certain enterprises - that are, in terms of size, quantity of production, distribution, number of employees similar to real industries - that have the characteristics suitable to give rise to a process of bottom up growth type.

Currently, the company's small size and low profitability do not allow the maintenance of employment opportunities and an appropriate degree of competitiveness at nationwide and worldwide level. However, through a policy of agglomeration Fucino agri-food businesses can eliminate or reduce some of the weaknesses and external threats detected: first, the network can reduce the competition between enterprises in respect of the resources used - as the water needed for irrigation; furthermore combining economic resources it can provide the area with appropriate infrastructure to manage the quantity of production and to expand sales, mainly by exploiting the trend of growth of exports that is high in the region, rather than a current number of products exported that is lower than the national average. 
A policy of agribusiness network increases the bargaining power of many small businesses, presumably increasing selling prices and thus the margin of each producer, compared to a reduction in costs due to the use of economies of scale and scope and strategies based on specialization and innovation of products.

So if local businesses are able to implement a strategy of agglomeration and get the benefits described, the agribusinesses network can proceed to a common branding strategy and create a brand that can make recognizable the products grown in plain of Fucino and it allows to compete in Italy and abroad.

\section{Limitations and Further Research}

The research arises from an analysis of secondary data collected by national agencies, making without a direct numerical measurements and quantitative surveys in the place and within enterprises subject of the work; furthermore, the Author emphasizes a high difficulty in finding data on the specific area of Fucino.

However, the present paper is the first part of a broader study that aims to achieve the processing of a detailed development plan of the agribusinesses of Fucino. Future research involves first an accurate survey of enterprises and their production and distribution capacity; therefore it is considered important to administer a questionnaire within the same, made up of both quantitative and qualitative surveys, aimed at measuring mainly the possession of structural and cultural features and willingness to establish business networks, with the assumption that the culture and objectives of entrepreneurs are a key aspect of the success of the aggregation strategies. These aspects are essential for future effective implementation of the strategy hypothesized.

\section{Managerial Implications}

As mentioned in the description of the results, the present study has several managerial implications in particular on the agri-food businesses; first of all, it provides a summary of the current state of the agro-food enterprises of Fucino, highlighting current limitations and weaknesses and subsequently assuming an organizational and managerial solution that is deemed appropriate for the model of Abruzzo businesses.

The reasons why a network strategy is the most appropriate and the benefits that this can bring to the producers of Fucino have been previously described. The work thus contains important information for policy makers and authorities, that will have access to a descriptive framework of the context and to a summary of the main characteristics of the agri-food businesses; they can act and legislate in order to improve the organizational situation and thereby increase competitiveness of products, for example through funding aimed to build manufacturing and logistical shared infrastructure. Strategic consequence of the establishment of a stable and functional business network, is the creation of common brand that would give awareness to crops grown in this area and transmit around the world their principal qualities.

However, the future analysis turns out to be decisive in order to assume substantial and specific strategy for place development; it will be manage through direct administration of questionnaires and it intends to detect more detailed data, the degree of openness of the companies, the tendency to collaboration, the will to overcome the structural and cultural limitations and to share a communal purpose.

The management model of agribusinesses network is definitely replicable in other Italian territories, which have limits similar to those described above although they produce excellent foods; in any case, the strategy has to consider local specificities and characteristics of individual firms. However, an effective implementation of the assumed strategy and the subsequent monitoring of results achieved, can provide useful information to spent in other areas of Italy.

\section{References}

Aiello, G., \& Donvito, R. (2007). L'evoluzione dei network per il marketing territoriale e l'attrazione degli investimenti. Mercati e Competitività, 1, 49-70.

Anderson, J. C., Hakansson, H., \& Johanson, L. (1994). Dyadic business relationships within a business network context. Journal of Marketing, 58(4), 1-15. http://dx.doi.org/10.2307/1251912

Aureli, S., \& Forlani, F. (2013). The role of network contracts in place brand management. Current usage and future possibilities of this new italian legislative instrument. Paper presented at 4th International Colloquium n Place Brand Management Strategic marketing in cities, regions and nations, Università di Aosta, 5th-6th September 2013.

Bagnasco, A., \& Rullani, E. (2008). Ragioni e contenuti del libro: guida alla lettura. Associazione Italiana della Produzione (a cura di), Reti di impresa oltre $i$ distretti. Nuove forme di organizzazione produttiva, di coordinamento e di assetto giuridico, Milano, Il Sole 24 Ore. 
BarNir, A., \& Smith, K. (2002). Interfirm alliance in the small business: the role of social network. Journal of small Business management, 40(3), 219-232. http://dx.doi.org/10.1111/1540-627x.00052

Becattini, G. (1998). Distretti industriali e made in Italy: le basi socioculturali del nostro sviluppo economico, Temi,79, Torino, Bollati Boringhieri.

Brasili, C., \& Ricci Maccarini, E. (2001). I sistemi locali dell'industria agroalimentare. Rosemberg \& Seller.

Bruderl, J., Preisendorfer, P., \& Ziegler, R. (1992). Survival canches of newly Founded organization. American sociologiacal review, 57, 227-242. http://dx.doi.org/10.2307/2096207

Brusco, S. (2008). Distretti industriali: lezioni per lo sviluppo. Una lettera e nove saggi (1990-2002), (a cura di) Anna Natali, Margherita Russo, Giovanni Solinas, Bologna, Il Mulino.

Caroli, M. G. (1996). Il marketing territoriale. Milano, Franco Angeli.

Caroli, M. G. (2006). Pubblico e privato nella logica del marketing territoriale. Sinergie Journal, 70, 45-63.

Contò, F., \& La Sala, P. (2011). Approccio territoriale e sviluppo locale. Il programma di sviluppo del distretto agroalimentare del Metapontino. (a cura di), Milano, Franco Angeli.

Contò, F., \& La Sala, P. (2012). Networks territoriali di sviluppo integrato per l'agroalimentare lucano, Milano, Franco Angeli.

Das, T. K., \& Teng, B. S. (2002). The dynamics of alliance conditions in the alliance development process. Journal of Management Studies, 39(5), 725-756. http://dx.doi.org/10.1111/1467-6486.00006

De Baldo, M. (2014). La Collaborazione aziendale come driver della competitività del settore e del territorio. Rivista delle scienze e del Turismo 1/2014.

Delahaye, B. L. (2000). Strategic human resource development. Milton, John Wiley \& Sons. http://dx.doi.org/10.4135/9781446216859

Depperu, D. (1996). Economia dei consorzi tra imprese. Milano, Egea.

Fanfani, R., \& Montresor, E. (1991). Filiere, multinazionali e dimensione spaziale. in "La Questione Agraria", 41.

Ferrari, S. (2000). Marketing dei distretti. Alcune riflessioni sulle applicazioni del marketing territoriale ai sistemi locali di imprese. Sinergie, 52, 253-283.

Giampaolo, A., Palumbo, S., \& Martino, M. (2013). L'agricoltura in Abruzzo: caratteristiche strutturali e risultati aziendali - Report 2013, Quaderno- Inea.

Granovetter, M. S. (1973). The strenght of weak ties. American Journal of Sociology, 76(6), 1360-1380. http://dx.doi.org/10.1016/b978-0-12-442450-0.50025-0

Gregori, G. L., Temperini, V., \& Perna, A. (2013). Quale possibile ruolo delle PMI nello sviluppo del marketing territoriale? Analisi del caso Land of Value. Piccola Impresa/Small Business, 1, 115-134.

Gulati, R., \& Gargiulo, M. (1999). Where do interorganizational networks come from? Amercian Journal of Sociology, 104(5), 1439-1493. http://dx.doi.org/10.1086/210179

Hanssen-Bauer, J., \& Snow, C. C. (1996). Responding to Hypercompetition: the structure and Processes of a regional learning network organization. Organization Science, 7(4), 413-427. http://dx.doi.org/10.1287/orsc. 7.4.413

Harrigan, K. R. (1998). Strategies for joint venture. Padova, Cedam.

Kheng-Hor, K., \& Munro-Smith, N. (1999). Reader-Friendly Strategic Management: A delightful blend of academic learning and Street-smart practices. Selangor Darul Ehsan: Pelanduk Publications.

Lerner, A. L. (1999). A Strategic Planning Primer for Higher Education. Northridge.

Lorenzoni, G. (1990) L'architettura di sviluppo delle imprese minori. Costellazioni e piccoli gruppi. Bologna, Il Mulino.

Marchini, I. (2005). Il governo della piccolo impresa, Vol. II. La gestione strategica, Genova, Aspi/Ins. Edit.

Nohria, N. (1992). Introduction: Is the network perspective a useful way of studying organizations? In N. Nohria \& R. Eccles (Eds.), Networks and organizations: structure, form and action. Cambridge, MA: Harvad University Press. 
Oliver, C. (1990). Determinants of interorganizational relationship: Integration and future directions. Academic of Management Review, 15, 241-265. http://dx.doi.org/10.5465/amr.1990.4308156

Park, S. H., \& Zhou, D. (2005). Firm heterogeneity and competitive dynamics in alliance formation. Academy of Management Review, 30(3), 531-544. http://dx.doi.org/10.5465/amr.2005.17293697

Park, S. H., Chen, R., \& Gallangher, S. (2002). Firm resources as moderators of the relationship between market growth and strategic alliances in semiconductor start-ups. Academic Management Journal, 45(3), 527-545.

Pfeffer, J. (1972). Interorganizational influence and managerial attitudes. The Academy of Management Journal, 15(3), 317-330.

Rullani, E. (2008). L'economia della conoscenza nel capitalismo delle reti. Sinergie, 49, 25-32.

Rullani, E. (2008). L'economia della conoscenza nel capitalismo delle reti. Sinergie, 26(76), 67-90.

Sakakibara, M. (1997). Evaluating Government-sponsored R\&D Consortia in Japan: Who Benefits and How? Research Policy, 26, 447-473. http://dx.doi.org/10.1016/s0048-7333(97)00018-8

Sansone, M. (2012). Place management: città territory marketing. Milano: McGraw-Hill.

Soda, G., Usai, A., \& Zaheer, A. (2004). Network memory: the influence of past and current networks on performance. Academy of Management Journal, 47, 893-906. http://dx.doi.org/10.2307/20159629

Sorensen, L., Vidal, R., \& Engström, E. (2004). Using soft OR in a small company-the case of Kirby. Eur $J$ Oper Res, 152, 555-570.

Street, T. C., \& Cameron, A. F. (2007). External Relationships and the Small Business: A review of Small Business Alliance and Network Research. Journal of Business Management, 45(2), 239-266.

Yadong, L. (2003). Industrial Dynamics and managerial networking in an emerging market: the Case of China. Strategic Management Journal, 24, 1315-1327.

Yin, X., Wu, J., \& Tsai, W. (2012). When Unconnected Others Connect: Does Degree Of Brokerage Persist After The Formation Of Multipartner Alliance? Organization Science, 2(6), 1682-1699. http://dx.doi.org/10.1002/smj.363

\section{Notes}

Note 1. This has been instrumental in the implementation inside of the business and the marketing function of the products, a function that enables firms in the network to offer customers products with higher service content, sometimes even with common brand (Centro Studi Confindustria 2011).

Note 2. http://www.treccani.it/enciclopedia/fucino/

Note 3. In fact, it is bordered to the north by the Velino massif, to the East and North-East with the SirenteMountains, to the south with those of the Marsi, to the west with the Simbruini.

Note 4. Centro Regionale di Studi e Ricerche Economico Sociali istituito dalle Camere di Commercio d'Abruzzo.

Note 5. Istituto Nazionale della Previdenza Sociale.

\section{Copyrights}

Copyright for this article is retained by the author(s), with first publication rights granted to the journal.

This is an open-access article distributed under the terms and conditions of the Creative Commons Attribution license (http://creativecommons.org/licenses/by/3.0/). 